\title{
A CFD Analysis of Rectangular Winglet Vortex Generators in Heat Exchanger
}

\author{
Miftakh F. Hanifan, Gunawan Nugroho", Ridho Hantoro, Sarwono \\ Department of Engineering Physics, Sepuluh Nopember Institute of Technology, Indonesia
}

Copyright $\bigcirc 2017$ by authors, all rights reserved. Authors agree that this article remains permanently open access under the terms of the Creative Commons Attribution License 4.0 International License

\begin{abstract}
A good performance of the heat exchanger will support energy efficiency and economic sustainability. One way to improve heat transfer coefficient is to increase turbulent flow by using vortex generators. The addition of vortex generators on heat exchanger will pose wake on the flow field which then reduce the stability of thermal boundary layer and enhance heat transfer coefficient. The effect of winglet vortex generators with the variations of angle of attack (AoA) is studied in this research. Each variation is applied in a single row and three rows of inline configurations. The results show that the addition of vortex generators with $160^{\circ}$ angle of attack and three rows of inline configuration improve heat transfer coefficient as $59 \%$ higher than conventional configurations.
\end{abstract}

Keywords Heat Exchanger, Vortex Generators, Heat Transfer Coefficient, Computational Fluid Dynamics

\section{Introduction}

Heat exchanger is a kind of important equipment and commonly applied in HVAC systems, power plants, waste heat utilization systems, and chemical processing systems [1]. One way to improve heat transfer coefficient on the air side is to increase the flow turbulence by using vortex generators. The addition of vortex generators into heat exchanger will cause longitudinal vertices in the flow field. The longitudinal vertex will decrease the stability of the thermal boundary layer and increase convection coefficient [2].

Research on the application of vortex generator as a heat transfer enhancement mechanism was conducted with attention to the location of placement, shape and its orientation. Research was performed by comparing the arrangement of inline and staggered heat exchanger tubes. Based on the research, it was found that there was an increase of $30 \%$ Nusselt number in the inline tube arrangement and $5.5 \%$ in the staggered tube arrangement [3]. According to the latest research, vortex generator with inline tube arrangement is more optimal for increasing heat transfer. In addition, the shape of the vortex generators is also discussed. The study of vector-shaped paired winglet generators was shown to improve the heat transfer process in heat exchangers $[4,5]$. Meanwhile, Tian et al. studied and compared the performance between delta shaped vortex generators and rectangular winglet at Reynolds number up to 1200 . The results show that rectangular winglets are better for increasing heat transfer compared to delta winglet pairs. Moreover, the arrangement of vortex generator also affects the heat transfer process. The three rows inline arrangement of vortex generators increased heat transfer up to $68 \%$ while single row of inline arrangement is only $44 \%$ [6]. The angle of attack also affects heat transfer process for the case of $160^{\circ}$, $165^{\circ}$, and $170^{\circ}$. The $160^{\circ}$ degree is the best for improving the fluid heat transfer coefficient around the tubes as observed by A. Sinha et al. [2].

Based on the previous research, numerical simulation is necessary for the application of vortex generators in heat exchanger with variation of AoA and their arrangement. In this work, the variation of winglet AoA and their configurations are performed to produce more turbulence and higher heat transfer coefficient.

\section{Research Methodology}

\subsection{Geometrical Parameter}

In this research, the design geometry from experimental research conducted by Joardar and Jacobi is applied [6]. It has the inline tube arrangement. The stream domain is $177.8 \mathrm{~mm} \times 101.6 \mathrm{~mm}$ size. The tube diameter is $10.6 \mathrm{~mm}$ with a thickness of $0.375 \mathrm{~mm}$. As for the vortex generator, the rectangular winglet type is implemented and the geometry and placement are illustrated in the following figure.

In Figure 1, the winglet angle of attack is $165^{\circ}$ which will be varied in $170^{\circ}, 165^{\circ}$ and $165^{\circ}$. The single-row and three-rows of inline variations are applied as shown in Figure 2. This variation is implemented according to the results of 
numerical simulation as in A. Sinha et al.'s study [2].

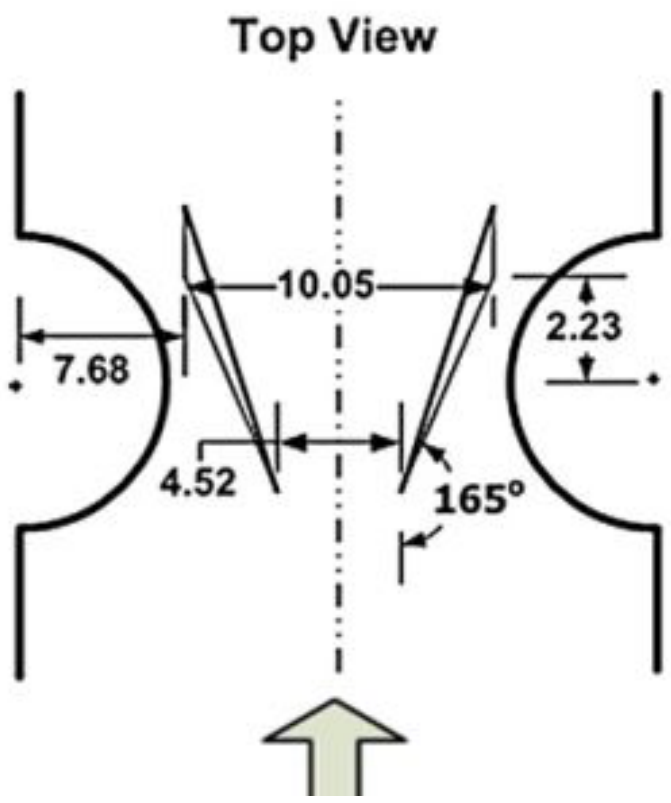

Figure 1. Winglets arrangement [6]

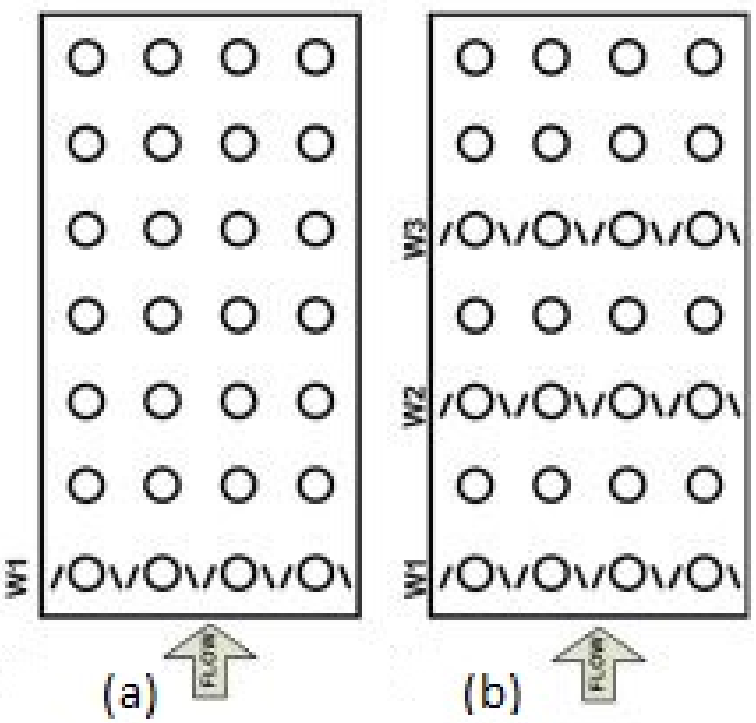

Figure 2. The arrangements of vortex generators (a) single row (b) three rows [6]

\subsection{Simulation}

\subsubsection{Pre-processing}

The pre-processing stage consists of geometric design, meshing, determination of boundary conditions and fluid properties. The applied geometric design is based on the specified reference which one example is depicted as follows:

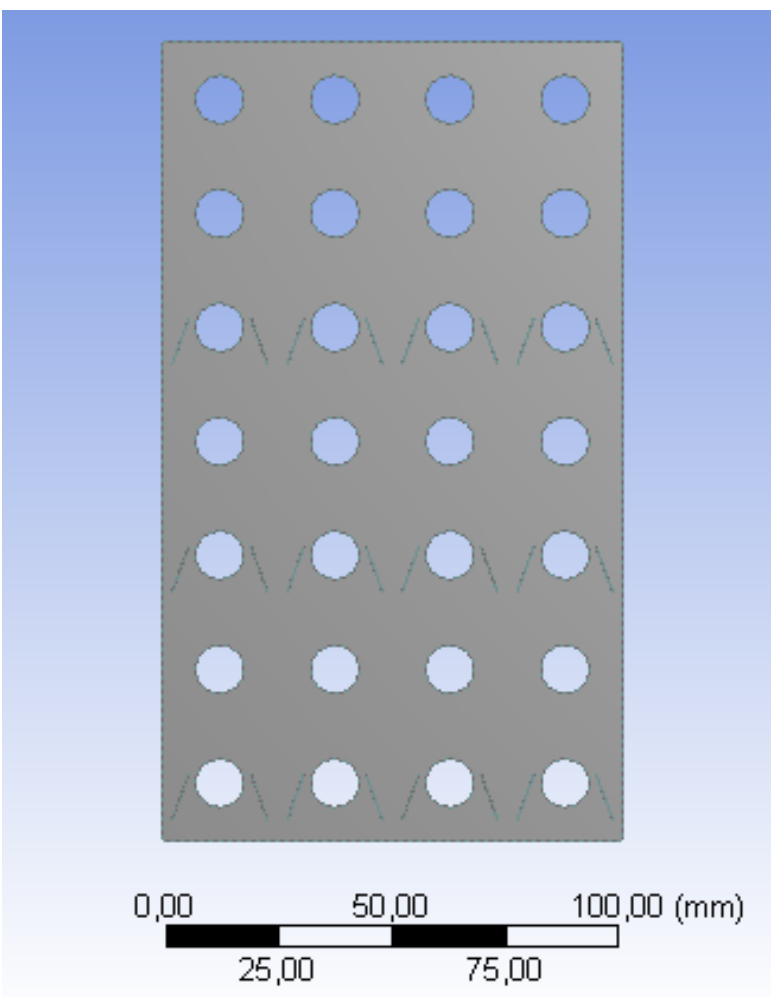

Figure 3. The geometric design

Figure 3 shows the variations of vortex generators in three rows arrangement with $160^{\circ}$ angle of attack. Inline arrangement for 28 tubes is also implemented. The number of vortex generators is 24 three rows configuration, while 8 for single configuration.

The next step is creating small elements which, each element calculates various mathematical equations such as mass conservation, energy, and momentum. On each side of the tube and vortex generators, the edge sizing of $0.001 \mathrm{~mm}$ is applied. The results are tabulated as following:

Table 1. Meshing

\begin{tabular}{|c|c|c|c|c|}
\hline Arrangement & $\begin{array}{c}\text { Angle of } \\
\text { Attack }\end{array}$ & Nodes & Elements & $\begin{array}{l}\text { Maximum } \\
\text { Skewness } \\
\end{array}$ \\
\hline \multicolumn{2}{|c|}{ Without Vortex Generator } & 509720 & 939959 & 0.88 \\
\hline \multirow{3}{*}{ Single row } & $160^{\circ}$ & 543404 & 1002751 & 0.81 \\
\hline & $165^{0}$ & 744808 & 1378970 & 0.94 \\
\hline & $170^{\circ}$ & 648968 & 1198599 & 0.92 \\
\hline \multirow{3}{*}{ Three rows } & $160^{\circ}$ & 779679 & 1440812 & 0.92 \\
\hline & $165^{0}$ & 984473 & 1823803 & 0.93 \\
\hline & $170^{\circ}$ & 904709 & 1673688 & 0.94 \\
\hline
\end{tabular}

\subsubsection{Processing}

After the meshing process, boundary conditions and mathematical parameters are determined. At this stage, all boundary conditions are adjusted to the conditions from the references. The boundary conditions are: 
Table 2. Boundary Conditions

\begin{tabular}{|c|c|c|}
\hline Boundary Condition & \multicolumn{2}{|c|}{ Details } \\
\hline \multirow{2}{*}{ Inlet } & Type & Velocity Inlet \\
\cline { 2 - 3 } & Air Velocity & $3.2 \mathrm{~m} / \mathrm{s}$ \\
\cline { 2 - 3 } & Temperature & $300 \mathrm{~K}$ \\
\hline \multirow{2}{*}{ Tube Wall } & Type & Stationary Wall \\
\cline { 2 - 3 } & Temperature & $330 \mathrm{~K}$ \\
\hline Outlet & Type & Outflow \\
\hline
\end{tabular}

As for the material properties, the conditions are:

Table 3. Material Properties

\begin{tabular}{|c|c|}
\hline Properties & Value \\
\hline Density & $2719 \mathrm{~kg} / \mathrm{m}^{3}$ \\
\hline Specific Heat & $871 \mathrm{~J} / \mathrm{kg} \mathrm{K}$ \\
\hline Thermal Conductivity & $202.4 \mathrm{~W} / \mathrm{m} \mathrm{K}$ \\
\hline
\end{tabular}

Then, the air inlet conditions are listed as:

Table 4. Inlet air properties

\begin{tabular}{|c|c|}
\hline Properties & Value \\
\hline Temperature & $300 \mathrm{~K}$ \\
\hline Density & $1.1614 \mathrm{~kg} / \mathrm{m}^{3}$ \\
\hline Specific Heat & $1007 \mathrm{~J} / \mathrm{kg} \mathrm{K}$ \\
\hline Kinematic Viscosity & $15.89 \mathrm{E}-06$ \\
\hline Thermal Conductivity & $0.0263 \mathrm{~W} / \mathrm{m} \mathrm{K}$ \\
\hline Prandtl & 0.707 \\
\hline
\end{tabular}

\subsubsection{Post-processing}

Furthermore, the standard K-epsilon is implemented in this work. This is due to its accuracy in the fluid flow calculations involving swirling flow, large pressure gradient, separation, and recirculation.

\section{Results and Discussion}

\subsection{Validation}

The result of velocity distribution is compared with the obtained data from Sinha [2] as shown in figure 4. In his study, the velocity distribution was simulated with inline tube arrangements without using vortex generators. It is shown the fluid flow similarity, which in the early rows a small blue region at tube end shows the point of stagnation. At this point, the fluid velocity is close to zero and the pressure increases. The area of flow separation is observed downstream. In overall, these two geometries have similarities in fluid phenomena around the tubes which validate the simulation.

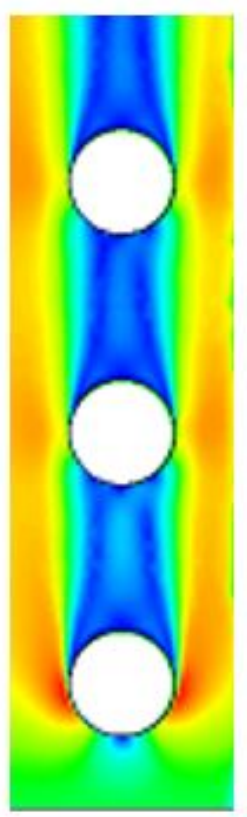

(a)

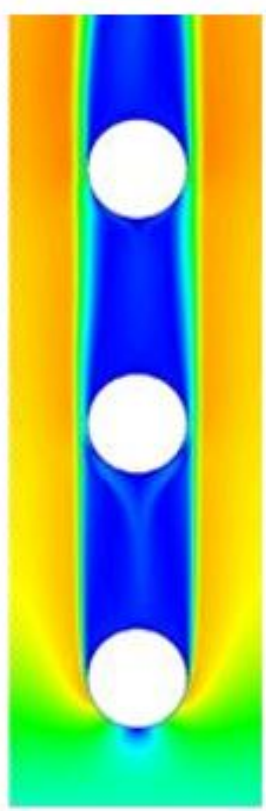

(b)
Figure 4. The comparison of velocity distribution

\subsection{Influence of Single Row and Three rows Configurations on Velocity Distribution}

In this simulation, the inlet air velocity is $3.2 \mathrm{~m} / \mathrm{s}$ in the direction of the positive y axis. Figure 5 depicts the increase air velocity at each gap between the vortex generators. The velocity increase is due to the area contraction through a small cross section. It is also observed that higher angle of attack decreases velocity between the gaps due to the widening of cross-sectional area between vortex generators. Figure 5(a) shows that the air velocity tends to increase with the addition of tube rows, whereas geometric design using vortex generators of figures 5(b) (c) (d) (e) (f) (g) illustrate the velocity increase from the initial row due to an increase of turbulence.

Different separation points are observed for single row and three rows configurations. Design with single row arrangement as in Figure 5 (b) (c) (d) shows the delay of the separation point is in the first row due to the vortex generators. While in the arrangement of three rows delay the separation point is in the first, third, and fifth row. The downstream wake is produced in each row and the impact is accumulated sequentially. 


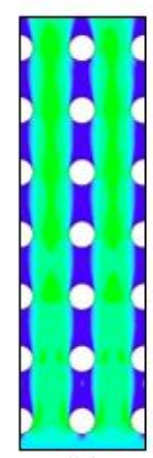

(a)

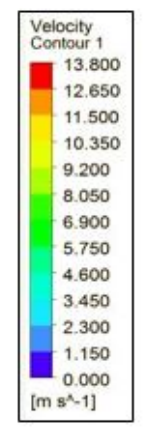

(b)

(e)

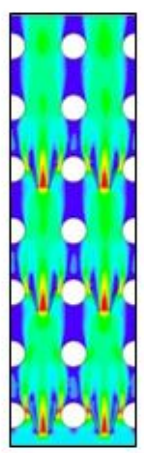

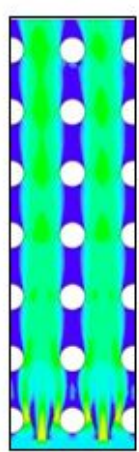

(c)

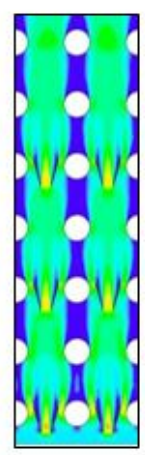

(f)

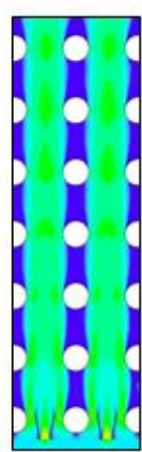

(d)

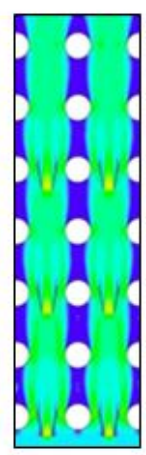

(g)
Figure 5. Influence of single row and three rows configurations on Velocity Distribution (a) Without VG (b) Single row $160^{\circ}$ (c) Single row $165^{\circ}$ (d) Single row $170^{\circ}$ (e) Three rows $160^{\circ}$ (f) Three rows $165^{\circ}$ (g) Three rows $170^{\circ}$

\subsection{Analysis of Single Row and Three Rows Configurations on Reynolds Number}

The calculation of Reynolds Numbers using the variable maximum velocity is listed in Table 5. It appears that there is a slight increase in Reynolds number by $110 \%$ from the design without vortex generators. It is seen that the highest flow turbulence is in the three rows configuration. This is because the flow turbulence in the three rows arrangement is always re-raised on each line. While the single row turbulence flow is only manipulated on the first line only. Meanwhile, Reynolds number decreases with respect to angle of attack. Higher angle of attack extends the cross-sectional area passed by the fluid flow, and generates smaller velocity and then, Reynolds number.

Table 5. The Influence of Single Row and Three Rows Configurations on Reynolds Number

\begin{tabular}{|c|c|c|}
\hline \multirow{3}{*}{ Arrangement } & Angle of Attack & Reynolds Number \\
\cline { 2 - 3 } & Without VG & 4451.99 \\
\hline \multirow{3}{*}{ Single row } & $160^{0}$ & 9598.30 \\
\cline { 2 - 3 } & $165^{0}$ & 7718.79 \\
\cline { 2 - 3 } & $170^{0}$ & 6533.61 \\
\hline \multirow{3}{*}{ Three rows } & $160^{0}$ & 9617.77 \\
\cline { 2 - 3 } & $165^{0}$ & 7890.03 \\
\cline { 2 - 3 } & $170^{0}$ & 7505.93 \\
\hline
\end{tabular}

Table 5 shows that the value of the highest Reynolds number is in the variation of three rows arrangement with $160^{\circ}$ angle of attack. It is found that large flow turbulence is related to the angle of attack which produces small cross-sectional area. However, this value is only $0.2 \%$ higher than the Reynolds number from a single row arrangement with $160^{\circ}$ angle of attack, which is an indicator of small velocity difference between two configurations, respectively.

\subsection{The Influence of Single Row and Three Rows Configurations on Nusselt Number}

Nusselt number is regarded as the ratio of convection to conduction heat transfer, which plays a fundamental role for the thermal performance. In this case, table 6 illustrates heat transfer performance with respect to angle of attack and row configurations.

Table 6. The influence of AoA and row configurations on Nusselt Number

\begin{tabular}{|c|c|c|}
\hline \multirow{3}{*}{ Arrangement } & Angle of Attack & Nusselt Number \\
\cline { 2 - 3 } & Without VG & 44.96 \\
\hline \multirow{3}{*}{ Single row } & $160^{\circ}$ & 72.95 \\
\cline { 2 - 3 } & $165^{\circ}$ & 63.59 \\
\cline { 2 - 3 } & $170^{\circ}$ & 57.25 \\
\hline \multirow{3}{*}{ Three rows } & $160^{\circ}$ & 73.04 \\
\cline { 2 - 3 } & $165^{\circ}$ & 64.47 \\
\cline { 2 - 3 } & $170^{\circ}$ & 62.48 \\
\hline
\end{tabular}

It is observed that the vortex generator increases Nusselt numbers up to $59 \%$ compared to geometric designs without vortex generators. This is similar to Reynolds number which increases in the design using vortex generators. Higher Nusselt number is inversely proportional to the angle of attack and the results are consistent with the explanation that velocity and turbulence is smaller with higher angle of attack. Moreover, the increase in Nusselt number for the three rows configuration is higher than a single row. However, the two arrangements only differed by $0.12 \%$ in overall because the velocity is almost the same.

\subsection{Analysis of the Influence of Single Row and Three rows of Vortex Generators on Temperature Distribution}

Figure 6 shows that the designs without vortex generators have more concentrated temperature until the last tubes compare to the implementation with vortex generator. The temperature distribution is more uniform in the rear tubes line for smaller angle of attack due to more intense turbulence. The flow turbulence will delay the separation point on the tube and increase the convection heat transfer between the tubes. Thus, the three-row arrangement has more distributed temperature than a single row. 


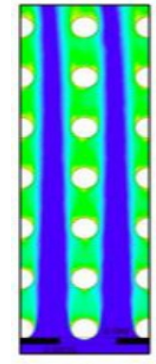

(a)

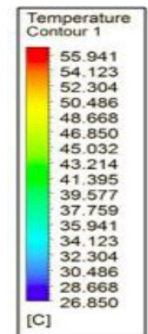

9.88

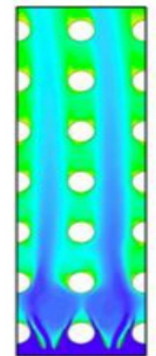

(b)

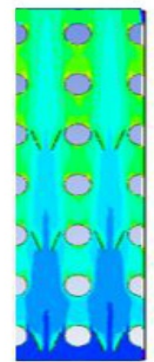

(e).

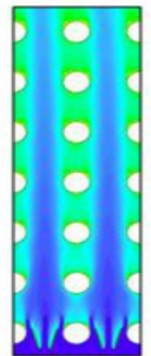

(c)

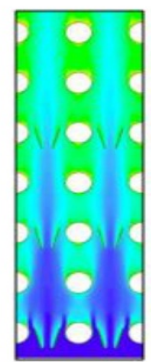

(f)

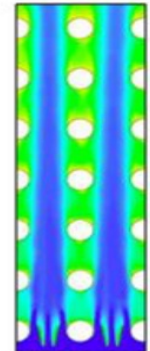

(d)

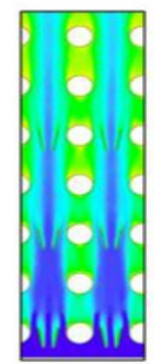

(g)
Figure 6. Analysis of the Influence of Single Row and Three rows of Vortex Generators on Temperature Distribution (a) Without VG (b) Single row $160^{\circ}$ (c) Single row $165^{\circ}$ (d) Single row $170^{\circ}$ (e) Three rows $160^{\circ}$ (f) Three rows $165^{\circ}(\mathrm{g})$ Three rows $170^{\circ}$

As described earlier, this research is based on the experiment conducted by Joardar et al. [2] which a comparison between a single row and three rows arrangement with fixed angle of attack was performed. The vortex generator managed to increase the airside convection coefficient by $68.8 \%$ for three rows configurations. Since this work produces $58 \%$ increase of convection coefficient, it is necessary for the future work to investigate this different value of whether the fluid flow phenomena is highly three-dimensional.

\section{Conclusions}

Research on a CFD analysis of vortex generator in the tube arrangements is conducted. This work implements the variation of AoA and vortex generator in a single and three rows configurations. The results show that the addition of vortex generators increases the maximum velocity around the tubes due to the area contraction of small cross section. It is also observed that there is an increase of Nusselt number up to $59 \%$ compared with those that do not apply vortex generators. The highest Nusselt number is on the $160^{\circ}$ angle of attack. Moreover, Nusselt number on the three rows configuration is $0.12 \%$ higher than a single row as well as more distributed temperature is achieved.

\section{REFERENCES}

[1] F.P. Incropera, D.P. Dewitt, T.L. Bergman, A.S. Lavine, Fundamentals of Heat and Mass Transfer 7th Edition, John Wiley \& Sons, 2011, USA.

[2] A. Sinha, H. Chattopadhyay, A. Kannan, G. Biswas, Enhancement of Heat Transfer in a Fin-Tube Heat Exchanger Using Rectangular Winglet Type Vortex Generators, International Journal of Heat and Mass Transfer, Vol. 101, 2016, pp. 667-681.

[3] A. Valencia, N.K. Mitra, Wing-Type Vortex Generators for Fin-and-Tube Heat Exchangers, Experimental Thermal and Fluid Science, Vol. 7, Issue 4, 1993, pp. 287-295.

[4] A.M. Jacobi, R.K. Shah, Heat Transfer Surface Enhancement through the Use of Longitudinal Vortices: A Review of Recent Progress, Experimental Thermal and Fluid Science, Vol. 11, Issue 3, 1995, pp. 295-309.

[5] L. Tian, Y. He, Y. Lei, W. Tao, Numerical Study of Fluid Flow and Heat Transfer in a Flat-Plate Channel with Longitudinal Vortex Generators by Applying Field Synergy Principle Analysis, Int. Commun. Heat Mass Transf., Vol. 36, No. 2, 2009, pp. 111-120.

[6] A. Joardar, A.M. Jacobi, Heat transfer Enhancement by Winglet-Type Vortex Generator Arrays in Compact Plain-Fin-and-Tube Heat Exchangers, International Journal of Refrigeration, Vol. 31, Issue 1, 2008, pp. 87-97. 